\title{
Conus Medullaris Syndrome as a Complication of Radioisotope Cisternography
}

\author{
Bek-San Park, Jinse Park, Seong-Ho Koh, Hojin Choi, Hyun-Jeung Yu, \\ Koo-Eun Lee, Young Joo Lee, Kyu-Yong Lee
}

\begin{abstract}
Objective: Conus medullaris syndrome (CMS) is a clinical neurologic syndrome caused by a conus medullaris lesion. CMS is a heterogeneous entity with various etiologies such as trauma or a space-occupying lesion. Multiple cases of CMS following spinal anesthesia have been reported, but CMS after radioisotope (RI) cisternography has not yet been reported. Methods: We present four patients who developed CMS after RI cisternography. Results: All experienced neurological deficits such as paraparesis, sensory loss, and urinary incontinence three to four days after RI cisternography. Two showed abnormalities on lumbar magnetic resonance imaging, and three had complete symptom resolution within ten weeks. Conclusions: The pathomechanism of the CMS is unclear, but we hypothesize that RI neurotoxicity might be responsible. It is possible that the use of low-dose ${ }^{99 \mathrm{~m}} \mathrm{Tc}-$ DTPA or an alternative diagnostic tool such as magnetic resonance cisternography could help to prevent this complication.
\end{abstract}

RÉSUMÉ: Le syndrome du cône médullaire comme complication de la cisternographie isotopique. Objectif : Le syndrome du cône médullaire (SCM) est un syndrome neurologique causé par une lésion du cône médullaire. Le SCM est une entité hétérogène à étiologie variable, dont un traumatisme ou une lésion envahissante. Bien que de nombreux cas de SCM suite à une anesthésie rachidienne aient été rapportés, aucun cas de SCM n'a été rapporté après une cisternographie isotopique. Méthode : Nous rapportons les observations cliniques de quatre patients qui ont présenté une SCM après une cisternographie isotopique. Résultats : Tous ont présenté des déficits neurologiques tels une paraparésie, une perte sensitive et de l'incontinence urinaire trois à quatre jours après la cisternographie isotopique. Deux avaient des anomalies à la résonance magnétique lombaire et les symptômes avaient complètement disparu dix semaines plus tard. Conclusions : Le mécanisme de la SCM n'est pas connu. Nous émettons l'hypothèse que la neurotoxicité radioisotopique pourrait en être responsable. Il est possible que l'utilisation de 99mTc-DTPA à faible dose ou un moyen diagnostique autre tel la cisternographie par résonance magnétique pourrait aider à prévenir cette complication.

Radioisotope (RI) cisternography is a frequently performed diagnostic tool for neurological diseases such as meningitis, normal pressure hydrocephalus, and intracranial hypotension. RI cisternography is known as a very safe procedure, but should be performed with caution because lumbar puncture and injection of RI are invasive. Several reports have described complications following RI cisternography, such as post-puncture headache and aseptic meningitis. ${ }^{1}$

Conus medullaris syndrome (CMS) is a clinical neurological syndrome caused by various etiologies. ${ }^{2}$ Common symptoms of CMS include lower back pain, sensory loss in the leg and perineal region, paraparesis, voiding difficulty, and bowel and sexual dysfunction. Conus medullaris syndrome as a complication of RI cisternography has not yet been reported. We encountered four patients who developed CMS following RI cisternography. The clinical features and possible mechanisms of CMS caused by RI cisternography are discussed in this report.

\section{Case histories}

\section{Patient 1}

A 51-year-old female with no history of medical problems visited our clinic for gait disturbance that had developed one year previously. On neurological examination, she showed glabellar sign and a wide gait without cognitive impairment or

From the Department of Neurology (BSP, SHK, HC, YJL, KYL), Hanyang University College of Medicine, Seoul; Department of Neurology (KEL, HJY), Bundang Jesaeng Hospital, Gyeonggi, South Korea; Department of Neurology (JP), Inje University Paik Hospital, Pusan, Korea.

Received July 25, 2011. Final Revisions Submitted November 24, 2011. Correspondence to: Seong-Ho Koh, Department of Neurology, Hanyang University College of Medicine, Gu-ri Hospital 249-1, Gyomun-dong, Guri-si, Gyeonggi-do, 471-701, Korea. Email: ksh213@hanyang.ac.kr 
urinary incontinence. Brain magnetic resonance imaging (MRI) showed communicating hydrocephalus with midbrain atrophy. We suspected normal pressure hydrocephalus and performed RI cisternography, with no complications before or after the procedure. Radioisotope cisternography revealed mild ventricular reflux and delayed cerebrospinal fluid (CSF) migration, but did not show the typical findings of normal pressure hydrocephalus.

The patient complained of sensory changes in both lower extremities four days after RI cisternography. Neurological examination demonstrated symmetric leg weakness of Medical Research Council (MRC) grade 4. Sensations for pain, temperature, vibration, and touch were decreased below bilateral L4 level. Deep tendon reflex (DTR) was normal. Lumbar MRI showed mild enhancement at the pia mater around the conus medullaris with T1-gadolinium enhancement (GE) (Figure 1). Six days after RI cisternography, the patient's symptoms showed some improvement, and she had recovered completely within ten days.

\section{Patient 2}

A 28-year-old female was admitted for evaluation of a headache. The headache was bilateral, dull, associated with nausea and vomiting, and aggravated by standing. No abnormal findings were noted on the neurological examination. Brain MRI revealed diffuse pachymeningeal thickening. Her CSF profile revealed $55 \mathrm{~mm} \mathrm{H}_{2} \mathrm{O}$ of pressure, a white blood cell (WBC) count of $0 / \mathrm{mm}^{3}$, red blood cell (RBC) count of $0 / \mathrm{mm}^{3}$, protein concentration of $42 \mathrm{mg} / \mathrm{dL}$, glucose concentration of $46 \mathrm{mg} / \mathrm{dL}$ and serum glucose level of $71 \mathrm{mg} / \mathrm{dL}$. RI cisternography showed CSF leakage around the L2, L3 and L5 levels. The patient experienced voiding difficulty three days after RI

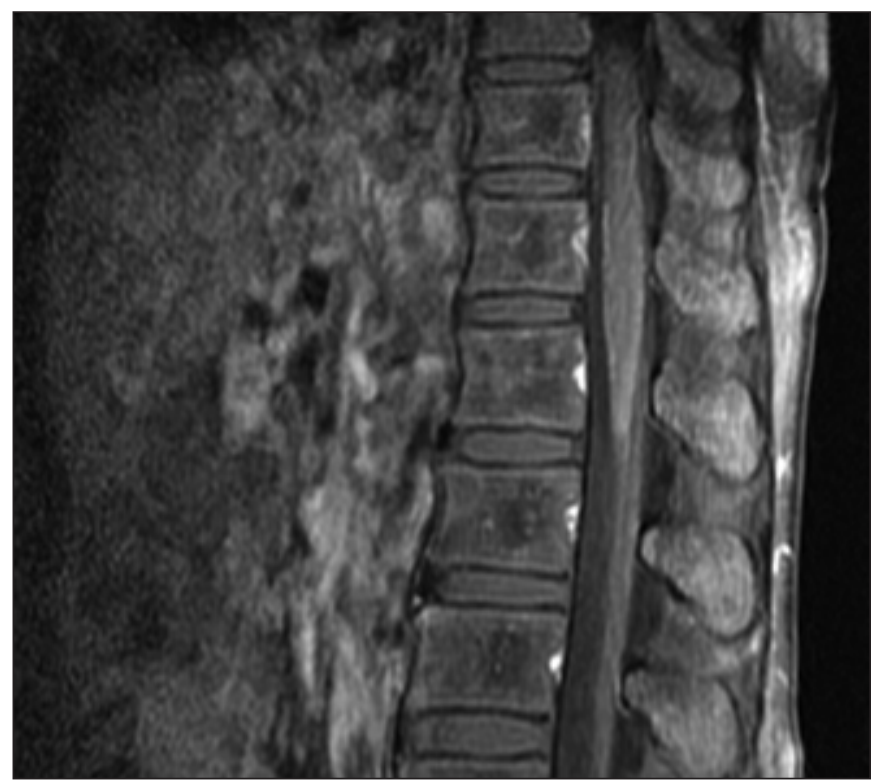

Figure 1: Magnetic resonance imaging using T1 gadolinium enhancement in Case 1. Mild enhancement is seen at the pia mater around the conus medullaris. cisternography. Neurological examination revealed paraparesis with MRC grade 4, and L5 sensory loss to pain and vibration bilaterally. Bilateral Babinski signs and hyperactive patella and Achilles reflexes were present. Minimal high signal intensity was noted around the conus medullaris in T1-GE of a lumbar MRI (Figure 2). We suspected that the toxic effect of a radioisotope might be responsible, so we started steroid injections (dexamethasone $15 \mathrm{mg} /$ day, intravenous). After ten weeks, neurological symptoms including paraparesis, sensory change, and urinary incontinence disappeared and the patient returned to normal. Her headache had also improved with an epidural blood patch, which was performed 15 days after CMS development.

\section{Patient 3}

A 50-year-old female who had been treated for Grave's disease with propylthiouracil was seen for a headache that had started two weeks previously. The headache had a bilateral occipital distribution and was characterized as a dull feeling not accompanied by nausea or vomiting. Brain MRI revealed a moderately enlarged lateral and fourth ventricle, suggesting hydrocephalus, so RI cisternography was performed. The patient had no history of head trauma, meningitis, or stroke. She had no cognitive decline, gait disturbance, or urinary incontinence, which would have indicated normal pressure hydrocephalus. CSF profiles were all within normal range, and we therefore suspected communicating hydrocephalus.

Vital signs were stable before and after RI cisternography. Four days later, she suffered from paraparesis, perineal sensory change, and voiding difficulty. The symptoms worsened and the patient was readmitted five days after RI cisternography. At admission, she showed prominent suprapubic distension without

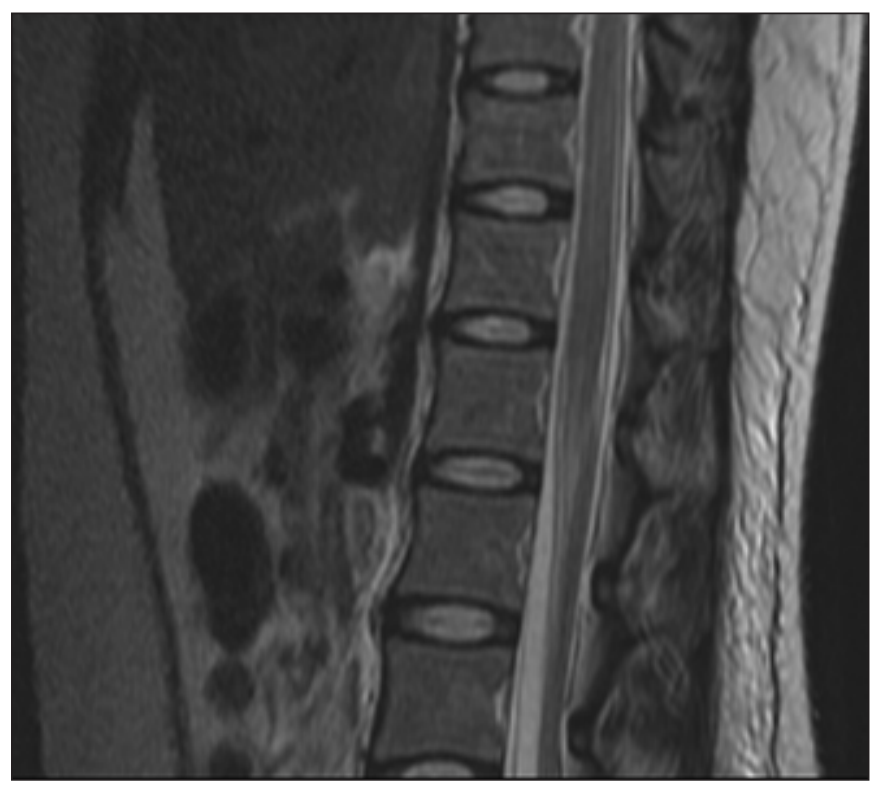

Figure 2: Magnetic resonance imaging using T2 weighting in Case 2. Minimal high signal intensity is seen around the conus medullaris. 
voiding sensation, indicating neurogenic bladder. We drained $600 \mathrm{~mL}$ of urine by Nelaton catheterization. Neurological examination demonstrated paraparesis with MRC grade 4, bilateral sensory loss to L5 with prominent saddle anesthesia and decreased anal sphincter tone. No pathologic reflex was noted.

We suspected CMS and performed lumbar MRI two days after the first symptoms, but no definite lesion was observed around the conus medullaris. We hypothesized that radioisotope toxic effects had produced an inflammatory process around the conus medullaris, and started steroid therapy (methylprednisolone $1 \mathrm{~g}$ /day, intravenous). After three days, her sensory symptoms and pararparesis had improved. Six days later, all neurological symptoms including voiding difficulty had returned to normal.

\section{Patient 4}

A 54-year-old female presented with a two-week history of headache accompanied by nausea and vomiting, and that increased in severity when standing. No abnormal finding was noted on the neurological examination. On admission day, brain MRI and CSF study was performed. Brain MRI revealed diffuse pachymeningeal thickening with enhancement, and CSF profiles were compatible with traumatic tap. Despite conservative treatment, the headache persisted. Seven days later, RI cisternography was performed for evaluation of intracranial hypotension. During the lumbar puncture for RI cisternography the patient complained of no complications other than a minimal tingling sensation in the left leg. Three days later, the patient complained of voiding difficulty. On neurological examination, she showed paraparesis with MRC grade 5-, paresthesia, and bilateral hypesthesia below the T11 level. Bilateral patellar and Achilles reflex showed hyperactivity compared with the thoracic or lumbar spinal cord region. The patient was discharged two weeks after RI cisternography without recovery. She has not recovered after six months and still suffers from mild sensory changes.

\section{Discussion}

In all four cases, CMS was ultimately diagnosed. All cases were women, and three were in middle age. We failed to identify any specific differences between the affected patients and the non-afflicted ones except that all the affected patients were female. The symptoms developed three to four days after RI cisternography. Three patients fully recovered and two patients showed abnormal findings on lumbar MRI. Case 3 suffered the most severe symptoms including weakness of anal sphincter tone. Case 4 has been suffering from sensory changes for almost six months, although her symptoms are much improved compared to her initial examination. No patients showed fever or signs of meningeal irritation. Lumbar puncture was easily performed between the L3-L4 intervertebral space in all patients. Three cases had complete recovery, but experienced severe depression and disability during the illness. A summary of the clinical data and neurological outcomes is in the Table.

These four cases were collected from three different hospitals over the five years from 2006 to 2011 . Four hundred and seventy two patients were examined during this period. The first case developed CMS in June, 2007 and the last case in May 2011.

A Techne ${ }^{\circledR}$ DTPA Kit made by FujiFil RI Pharma Company was used for RI cisternography. It contained calcium chloride dehydrate and was stored at $-25^{\circ} \mathrm{C}$. We added $555 \mathrm{MBq}$ of $99 \mathrm{~m}-$ Technetium, followed by $20 \mathrm{ml}$ of saline, and used $1 \mathrm{ml}$ aliquots of the mixture. The kit contains $20 \mathrm{mg}$ of DTPA kit, so we employed $1 \mathrm{mg}$ of ${ }^{99 \mathrm{~m}} \mathrm{Tc}-\mathrm{DTPA}$ per person. For the procedures, we used only sterile syringes, vials, and gloves.

The cornus medullaris is the finely tapered distal end of the spinal cord and is usually located between the first and second lumbar vertebrae in an average adult. ${ }^{2}$ Injury to the conus

Table: A summary of the clinical data and neurological outcomes

\begin{tabular}{|c|c|c|c|c|}
\hline Case & 1 & 2 & 3 & 4 \\
\hline Age & 56 & 28 & 50 & 54 \\
\hline Sex & female & female & female & female \\
\hline \multicolumn{5}{|l|}{ Symptoms } \\
\hline Paraparesis & Yes & Yes & Yes & Yes \\
\hline Sensory loss & Yes & Yes & Yes & Yes \\
\hline Voiding difficulty & No & Yes & Yes & Yes \\
\hline Bowel dysfunction & No & No & Yes & No \\
\hline Pain in legs or back & Yes & No & No & No \\
\hline Babinski`s sign & Positive & Positive & Negative & Negative \\
\hline DTR & Normal & Hyperactive & Normal & Hyperactive \\
\hline $\begin{array}{l}\text { Duration from } \quad \text { RI } \\
\text { cisternography to CMS (days) }\end{array}$ & 4 & 3 & 4 & 3 \\
\hline $\begin{array}{l}\text { CMS symptom duration } \\
\text { (days) }\end{array}$ & 10 & 70 & 6 & 180 \\
\hline Spinal MRI & Abnormal & Abnormal & Normal & Normal \\
\hline Neurologic sequelae & No & No & No & Yes \\
\hline
\end{tabular}

CMS: conus medullaris syndrome 
medullaris presents with symmetric motor weakness, sensory loss, voiding difficulty, defecation difficulty, and sexual dysfunction. ${ }^{3}$ Reflexes are diminished. The typical causes of CMS are trauma. ${ }^{3}$ For four years, Tayler et al surveyed patients of CMS caused by trauma and found that patients with a traumatic conus lesion have a good prognosis. ${ }^{3}$ Several reports have described CMS caused by a space-occupying lesion such as a congenital cyst, tumor, or vascular malformation. ${ }^{4-6}$ Congenital anomalies such as tethered cord syndrome and syrinx have also been reported..$^{7,8} \mathrm{~A}$ few cases of conus medullaris infarction were reported. ${ }^{9}$ Two reports have described CMS as a complication of spinal anesthesia, ${ }^{2,10}$ however no reports have described CMS following RI cisternography.

Although the precise factor responsible for complications after RI cisternography remains unclear, we postulate some possible mechanisms. First, we suspected a direct spinal needle injury to the conus medullaris as a possible etiology. Although lumbar punctures were performed at the L3-L4 interspace by experts in all cases, we could not exclude the possibility of needle injury. We used Tuffier's line which connects the posterior iliac crests to determine the level of needle insertion by palpation. Tuffier's line is generally found in the L4-5 intervertebral space. However, Tuffier's line is not a constant consistent indicator. Van Gessell et al demonstrated that $59 \%$ of dural punctures were performed one or two spaces higher than assumed. ${ }^{11}$ More recently, Broadbent et al found that when a group of experienced anesthetists believed they had identified L3-4, the selected space was one to four segments higher $85 \%$ of the time. ${ }^{12}$ Although the cord usually ends at the L1-L2 interspace, it may extend as low as L3. ${ }^{2}$ Thomson et al found that it reached L2 in $43 \%$ of women and $27 \%$ of men. ${ }^{13}$ It seems to be related to the fact that our patients were all woman. Therefore, we should have considered a direct injury by a spinal needle as an etiology of CMS. However, direct injury from a spinal needle to the conus medullaris causes immediate pain and neurological deficit. $^{2}$ Most patients did not experience pain during the lumbar puncture except Case 4, and all patients developed CMS three to four days later. These clinical findings contradict the hypothesis of direct needle injury.

Another possible etiology we strongly suspect is neurotoxicity of the RI around the conus medullaris. Usually, ${ }^{111}$ In-DTPA or ${ }^{99 m}$ Tc-DTPA is used as tracer for RI cisternography. The major limitation of ${ }^{99 \mathrm{~m} T c-D T P A}$ is that it has a short half-life. Therefore, ${ }^{111}$ In-DTPA which can be imaged over several days might be more appropriate for evaluating CSF leaks; however it is not available in Korea. In addition, the feasibility and usefulness of delayed imaging in ${ }^{99 \mathrm{~m} T c-D T P A}$ cisternography has been proven ${ }^{14}$ although the image of ${ }^{99} \mathrm{~m} \mathrm{Tc}-$ DTPA after a 48 hour delay is poorer than that of ${ }^{111}$ In-DTPA. We administered ${ }^{99 \mathrm{~m}} \mathrm{Tc}-\mathrm{DTPA}$ to all patients by intrathecal injection. Levine and Jayabalan surveyed complications of RI cisternography for six years. ${ }^{1}$ Complications of RI cisternography included fever, aseptic meningitis, allergic reaction, facial edema, and asymptomatic CSF abnormality. Aseptic meningitis was the most common complication. ${ }^{1,15,16}$ The exact mechanism was uncertain, although chemical irritation, sensitization, and contamination were suggested. James et al detected an endotoxin by Limulus test in aseptic meningitis patients after RI cisternography. ${ }^{15}$ To exclude complications caused by endotoxins, we tested for their presence before using the calcium-containing DTPA and did not detect any. Jonas et al reported a case of neurogenic bladder induced by RI cisternography, and suggested that chemical or physical irritation, rather than a pyrogen, might be the cause of the complication. ${ }^{17}$ All the previously reported cases ${ }^{1,15,16}$ displayed the typical findings of meningitis such as fever, stiff neck, and increased cell counts and protein in the CSF. Aseptic meningitis as a complication of RI cisternography is not life-threatening and has a favorable prognosis. ${ }^{1,15,16}$ Most reactions to RI might be attributed to a high albumin content of the RI1 but the ${ }^{99 \mathrm{~m}} \mathrm{Tc}-$ DTPA that we used contained no albumin, and our patients developed CMS without meningitis. Why the toxic reaction focally occurred in the conus medullaris without systemic reaction is uncertain. The conus medullaris may be susceptible to RI neurotoxicity. We suggest that gravity affects the distribution of RI, and the sacral portion might be particularly susceptible to injury by RI neurotoxicity. Lidocaine and tetracine used as spinal anesthesia have been reported to induce CMS. ${ }^{10,18}$ In these reports, misdistribution was caused by the catheter, and high doses of anesthetics damaged the conus medullaris. The clinical presentations such as onset time and recovery rate of these patients resembled our cases.

We propose another possible mechanism to explain our cases, in which the free acid form of sodium salts of ${ }^{99 \mathrm{~m} T c-D T P A}$ chelated $\mathrm{Ca}^{2+}$ and/or $\mathrm{Mg}^{2+}$ ions in the CSF. Removal of these ions from the CSF produces neurological deficits. ${ }^{19}$ A number of serious neurological adverse reactions, presumably related to sequestration of ions in the CSF, have been reported after intrathecal injection of 99mTc-DTPA products. ${ }^{20,21}$ Calciumcontaining DTPA is known to be safer than the free acid or sodium DTPA, and the recommended dose of injected RI is no more than $1 \mathrm{mg} \cdot{ }^{20}$

We note that early MRI evaluation is helpful in detecting conus medullaris lesions if CMS is suspected after RI cisternography. Only two patients who received MRI within two days showed abnormal MRI findings, in contrast to other patients who received MRI after three days. This suggests that lesions of the conus medullaris caused by RI cisternography might be reversible and easily recovered.

Although RI cisternography is the gold standard to define CSF leakage, caution in performing RI cisternography is warranted because it can cause many complications. Recently, GE MR cisternography was suggested to be safe and effective in accurately detecting lesion sites without risk of radiation exposure. $^{22}$ This seems to be an excellent alternative to RI cisternography.

We offer the following suggestions for cisternography performance to minimize complications:

1) Use calcium-containing DTPA and administer no more than 1 $\mathrm{mg}$.

2) Perform the lumbar puncture at the lowest lumbar spinal level possible.

3) Monitor vital signs and examine for neurological deficit before and after intrathecal injection.

4) Consider MR cisternography as an alternative to RI cisternography.

We conclude that constant attention to safety and carefully informed consent from patients are necessary for performing RI cisternography. 


\section{ACKNOWLEDGEMENTS}

Drs. Bek-San Park and Jinse Park participated in acquisition, organization, and review of data and drafting of the manuscript. These two authors contributed equally to this work. Drs. Hojin Choi, Hyun-Jeung Yu, Koo-Eun Lee, Young Joo Lee, and KyuYong Lee participated in acquisition, organization, review and interpretation of data. Seong-Ho Koh participated in review and interpretation of data.

This work was supported by a grant from the Research Fund of Hanyang University (HY-2010-MC).

\section{REFERENCES}

1. Levine MC, Jayabalan V. Complications of isotope cisternography. Ann Neurol. 1977;1(2):172-6.

2. Reynolds F. Damage to the conus medullaris following spinal anaesthesia. Anaesthesia. 2001;56(3):238-47.

3. Taylor TK, Coolican MJ. Injuries of the conus medullaris. Paraplegia. 1988;26(6):393-400.

4. Mathew P, Todd NV. Intradural conus and cauda equina tumours: a retrospective review of presentation, diagnosis and early outcome. J Neurol Neurosurg Psychiatry. 1993;56(1):69-74.

5. Hida K, Iwasaki Y, Cho K, Imamura H, Abe H. Gliomas of the conus medullaris. Paraplegia. 1994;32(1):52-8.

6. Sigal R, Denys A, Halimi P, Shapeero L, Doyon D, Boudghene F. Ventriculus terminalis of the conus medullaris: MR imaging in four patients with congenital dilatation. AJNR Am J Neuroradiol. 1991;12(4):733-7.

7. Sridhar K, Ramamurthi R, Vasudevan MC. Isolated eccentric syrinx of the conus medullaris simulating a tumour. Br J Neurosurg. 1999;13(4):423-5.

8. Warder DE, Oakes WJ. Tethered cord syndrome: the low-lying and normally positioned conus. Neurosurgery. 1994;34(4):597-600.

9. Ohbu S, Ishimoto A, Honda M, Fukuda H, Hata Y, Tada S. Infarction of the conus medullaris. Eur Neurol. 1990;30(6): 343-4.

10. Waters JH, Watson TB, Ward MG. Conus medullaris injury following both tetracaine and lidocaine spinal anesthesia. J Clin Anesth. 1996;8(8):656-8.
11. Van Gessel EF, Forster A, Gamulin Z. Continuous spinal anesthesia: where do spinal catheters go? Anesth Analg. 1993;76 (5):1004-7.

12. Broadbent CR, Maxwell WB, Ferrie R, Wilson DJ, Gawne-Cain M, Russell R. Ability of anaesthetists to identify a marked lumbar interspace. Anaesthesia. 2000;55(11):1122-6.

13. Thomson A. Fifth Annual Report of the Committee of Collective Investigation of the Anatomical Society of Great Britain and Ireland for the Year 1893-94. J Anat Physiol. 1894;29(Pt 1): 35-60.

14. Bom HS, Song HC, Kim JY. The usefulness of 48 hour imaging in Tc-99m DTPA cisternography. Korean J Nucl Med. 1994;28(3): 313-16.

15. Cooper JF, Harbert JC. Endotoxin as a cause of aseptic meningitis after radionuclide cisternography. J Nucl Med. 1975;16(9): 809-13.

16. Barnes B, Fish M. Chemical meningitis as a complication of isotope cisternography. Neurology. 1972;22(1):83-91.

17. Jonas S, Braunstein P. Neurogenic bladder as a complication of isotope cisternography. J Nucl Med. 1972;13(10):763-4

18. Lui AC, Munhall RJ, Winnie AP, Selander D. Baricity and the distribution of lidocaine in a spinal canal model. Can J Anaesth. 1991;38(4 Pt 1):522-6.

19. Ponto JA. Special safety considerations in preparation of technetium Tc-99m DTPA for cerebrospinal fluid-related imaging procedures. J Am Pharm Assoc. 2008;48(3):413-16.

20. Verbruggen AM, de Roo MJ, Klopper JF. Technetium-99m diethylene triamine pentaacetic acid for intrathecal administration: are we playing with fire? Eur J Nucl Med. 1994; 21(3):261-3.

21. Hesslewood SR. Adverse reaction to Tc-99 m DTPA. Eur J Nucl Med. 1993;20(6):567.

22. Albayram S, Kilic F, Ozer H, Baghaki S, Kocer N, Islak C. Gadolinium-enhanced MR cisternography to evaluate dural leaks in intracranial hypotension syndrome. AJNR Am J Neuroradiol. 2008;29(1):116-21. 